\title{
Occurrence of Equatorial Plasma Bubbles during Intense Magnetic Storms
}

\author{
Chao-Song Huang \\ Boston College, Institute for Scientific Research, 400 St Clement's Hall, 140 Commonwealth Avenue, Chestnut Hill, \\ MA 02467, USA \\ Correspondence should be addressed to Chao-Song Huang, chaosong.huang@bc.edu
}

Received 8 February 2011; Accepted 29 April 2011

Academic Editor: Lucilla Alfonsi

Copyright () 2011 Chao-Song Huang. This is an open access article distributed under the Creative Commons Attribution License, which permits unrestricted use, distribution, and reproduction in any medium, provided the original work is properly cited.

\begin{abstract}
An important issue in low-latitude ionospheric space weather is how magnetic storms affect the generation of equatorial plasma bubbles. In this study, we present the measurements of the ion density and velocity in the evening equatorial ionosphere by the Defense Meteorological Satellite Program (DMSP) satellites during 22 intense magnetic storms. The DMSP measurements show that deep ion density depletions (plasma bubbles) are generated after the interplanetary magnetic field (IMF) turns southward. The time delay between the IMF southward turning and the first DMSP detection of plasma depletions decreases with the minimum value of the IMF $B_{z}$, the maximum value of the interplanetary electric field (IEF) $E_{y}$, and the magnitude of the Dst index. The results of this study provide strong evidence that penetration electric field associated with southward IMF during the main phase of magnetic storms increases the generation of equatorial plasma bubbles in the evening sector.
\end{abstract}

\section{Introduction}

Intense geomagnetic storms occur when the solar wind with strong, persistent southward interplanetary magnetic field (IMF) impacts on the Earth's magnetosphere. The interplanetary electric field (IEF) associated with southward IMF penetrates to the equatorial ionosphere, creating an eastward electric field on the dayside and a westward electric field on the nightside. Penetration electric fields in the ionosphere have been extensively studied with the incoherent scatter radar chain including the Sondrestrom, Millstone Hill, Arecibo, and Jicamarca radars at $\sim 75^{\circ} \mathrm{W}$ geographic longitude, as well as with other space-based and groundbased measurements [1-14], and numerically simulated with global ionospheric models [15-18]. Huang et al. [6, 7, 14] and Huang [11] found that penetration electric fields in the ionosphere can last for several hours without obvious attenuation during continuous southward IMF. Huang et al. [8] reported that penetration efficiency, which is defined as the ratio of the change of the equatorial ionospheric electric field to the change of the IEF, is $\sim 10 \%$ on the dayside.

The purpose of this paper is to study how penetration electric fields affect the generation of plasma bubbles in the evening equatorial ionosphere during intense magnetic storms. Plasma bubbles are first generated in the bottomside $\mathrm{F}$ region and then penetrate the $\mathrm{F}$ peak to the topside F region [19-32]. However, the occurrence of equatorial plasma bubbles during magnetic storms has not been fully understood. In earlier studies, some investigators suggested that magnetic storms suppressed equatorial spread F (ESF) in the evening sector. Rastogi et al. [33] reported that the enhanced magnetic activity reduced the occurrence of equatorial radio scintillations and spread $\mathrm{F}$ during premidnight hours. Watanabe and Oya [34] found that the occurrence probability of plasma bubbles decreased during magnetically active periods for the local time in premidnight. Singh et al. [35] found that increased magnetic activity inhibited premidnight bubble generation. Palmroth et al. [36] analyzed the correlation between the occurrence of equatorial density depletions and the Kp index and concluded that the magnetic activity decreased the number of depletions in the evening sector.

Recent studies showed that magnetic activity may increase the occurrence of equatorial plasma bubbles. Fejer et al. [37] suggested that penetration electric fields associated 
with southward IMF during the early main phase of magnetic storms is eastward in the evening sector and will drive the equatorial $\mathrm{F}$ region to move upward, producing favorable condition for the excitation of the Rayleigh-Taylor instability. Huang et al. [38, 39] found that plasma bubbles develop in the evening sector during the early stages of high magnetic activity periods, which suggests that penetration electric fields during southward IMF are responsible for driving plasma bubbles. Basu et al. [40, 41] suggested that the eastward penetration electric field at dusk during the main phase of magnetic storms causes a rapid lift of the equatorial ionosphere and sets off plasma instabilities to form plasma bubbles or bite-outs. Huang [11] and Huang et al. [14] examined the measurements of the Defense Meteorological Satellite Program (DMSP) satellite and found that the penetration electric field at dusk is eastward, lasts for several hours during the main phase of magnetic storms, and causes large upward ion drift in the equatorial ionosphere. The numerical simulations of Keskinen et al. [26] show that a prompt eastward penetration electric field during magnetic storms can increase the vertical drift of the evening equatorial $\mathrm{F}$ region plasma and result in the generation of plasma bubbles. Kelley and Retterer [13] used measured electric fields as input into the ionospheric model and successfully reproduced the large-scale plasma bubbles in the equatorial ionosphere during an intense magnetic storm. The simulation results are in good agreement with the measurements of the Jicamarca incoherent scatter radar.

Recent studies have increased the understanding of the influence of geomagnetic activity on the generation of equatorial plasma bubbles. However, further investigations are necessary to determine how rapidly plasma bubbles are generated in response to penetration electric fields and how the response time of the ionosphere varies with the interplanetary electric field and with the strength of geomagnetic activity. In this paper, we present the DMSP satellite measurements of the equatorial ionospheric ion velocity and density in the evening sector and perform a statistical analysis of the occurrence of plasma bubbles during the main phase of intense magnetic storms.

\section{Observations}

We first present examples of penetration electric fields during magnetic storms. Figures $1(\mathrm{a})-1(\mathrm{~d})$ show the IMF $B_{z}$ component, the IEF $E_{y}$ (dawn-to-dusk) component, the ion vertical velocity in the equatorial ionosphere, and the Dst index on 9 November 2004, respectively. The solar wind data were measured by the Advanced Composition Explorer (ACE) satellite located at $\sim 220 R_{E}$ upstream and have been shifted to the Earth's bow shock nose with the minimum variance analysis technique developed by Weimer et al. [42]; the IMF components are plotted in the GSM coordinate. In all cases analyzed in this paper, the solar wind and IMF data have been shifted to the bow shock nose with the above technique.

The IMF was weakly southward or close to zero before 1900 UT and became strongly southward between 1900 and 2043 UT, as indicated by the yellow shading. The first storm of this sequence started at $\sim 2000$ UT on 7 November, and the Dst index reached a minimum value of $-373 \mathrm{nT}$ at 0600 UT on 8 November and remained below -100 nT on 8 9 November. The southward IMF between 1900 and 2043 UT on 9 November caused a significant intensification of the storm, and the Dst index reached another minimum value of $-223 \mathrm{nT}$ at $2100 \mathrm{UT}$. The Jicamarca incoherent scatter radar was in the afternoon sector (1400-1543 LT) during the period of southward IMF. Shown in Figure 1(c) is the ion vertical velocity measured by the Jicamarca radar. The maximum upward ion velocity at $\sim 2000$ UT reached $\sim 130 \mathrm{~m} \mathrm{~s}^{-1}$. The enhanced ionospheric ion drift had a shape similar to that of the IEF and was obviously caused by penetration electric field. The penetration electric field lasted for 1.7 hours during the period of storm intensification.

Because equatorial spread $\mathrm{F}$ and plasma bubbles occur in the postsunset sector, we need to determine how the plasma drift in the evening ionosphere responds to magnetic storms. In this study, we use the measurements of the DMSP F13 satellite to derive the ion drift velocities. The orbit of F13 crosses the equator near $1800 \mathrm{LT}$ at an altitude of $848 \mathrm{~km}$. Because ion drift velocities vary with latitude, we perform second-order polynomial fits to data taken between $\pm 10^{\circ}$ magnetic latitudes and use the polynomial-fit values at the magnetic equatorial crossing to represent the ion drift velocity at the magnetic equator. To quantify storm-time ion drift enhancements, it is necessary to establish quiettime references. This is important because ion velocity data measured by satellites may include offsets. The quiet-time reference is derived from the data during duskside equatorial crossings during 10 quiet days, 5 days just before and after the magnetic storm. The details of the DMSP data processing are given by Huang et al. [14].

Figures $1(\mathrm{e})-1(\mathrm{~h})$ show the storm case on $29-31$ October 2003. The shaded intervals represent the periods of southward IMF. The ionospheric ion drift velocity was measured by the DMSP F13 satellite. The green line in Figure $1(\mathrm{~g})$ is the quiet-time reference accumulated near the time of the October 2003 storm, and the red dots represent the ion vertical velocity on the storm days. The ion vertical velocities, including the reference, are mostly negative (downward) during the period of interest in this case. F13 data were acquired near the 1800 LT where the prereversal enhancement should be in evidence during both quiet and main-phase intervals. Downward drifts apparent in Figure $1(\mathrm{~g})$ indicate a bias in value in F13 measurements of the ion vertical velocity. However, the ion velocity differences between the storm-time and reference values were caused by the penetration electric fields and reached $\sim 120 \mathrm{~m} \mathrm{~s}^{-1}$. In particular, the enhanced ion vertical drift lasted for $\sim 6$ hours during the second and third shaded periods when the geomagnetic activity was strengthening [14].

The DMSP measurements presented in Figures $1(\mathrm{e})-1(\mathrm{~h})$ reveal important features of the equatorial ionospheric ion vertical drift at dusk in response to magnetic storms. The ion vertical drift is significantly enhanced in the upward direction. The enhanced upward ion drift can last for up to 6 hours during continuous southward IMF and will move the F region to high altitudes conducive for the generation of the Rayleigh-Taylor instability and plasma bubbles. 


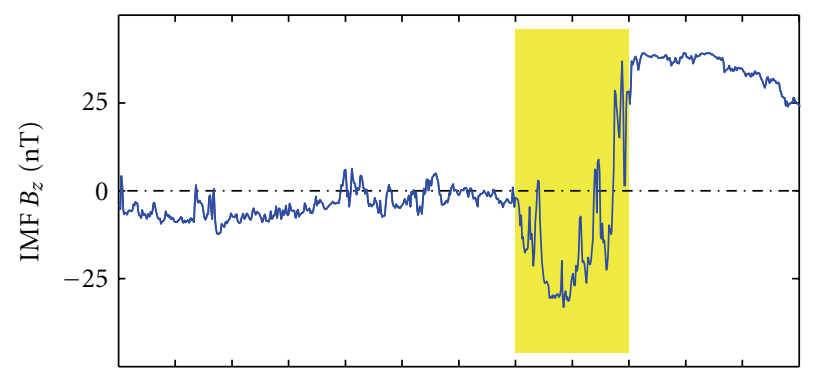

(a)

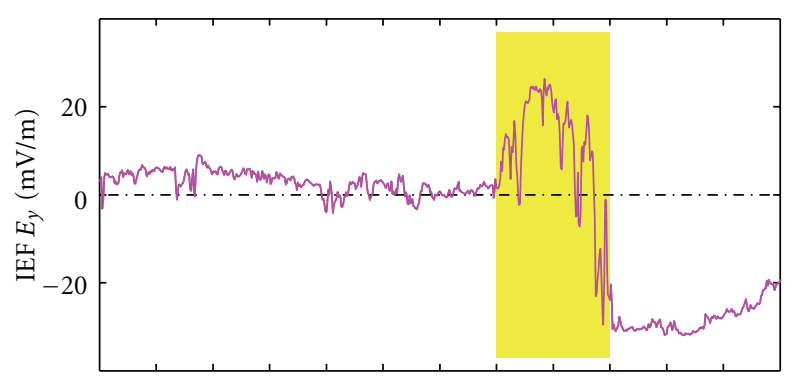

(b)

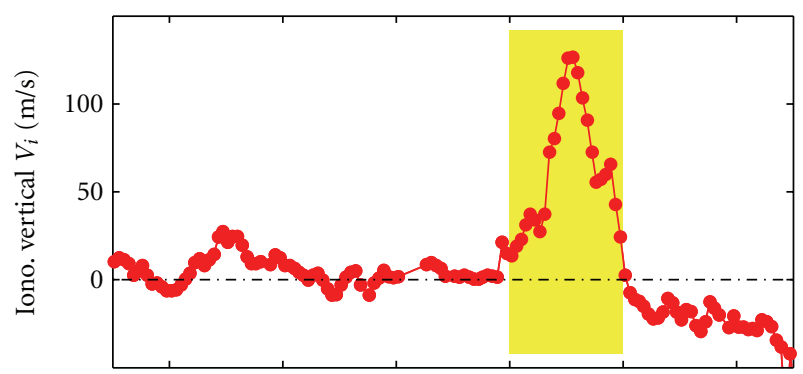

(c)

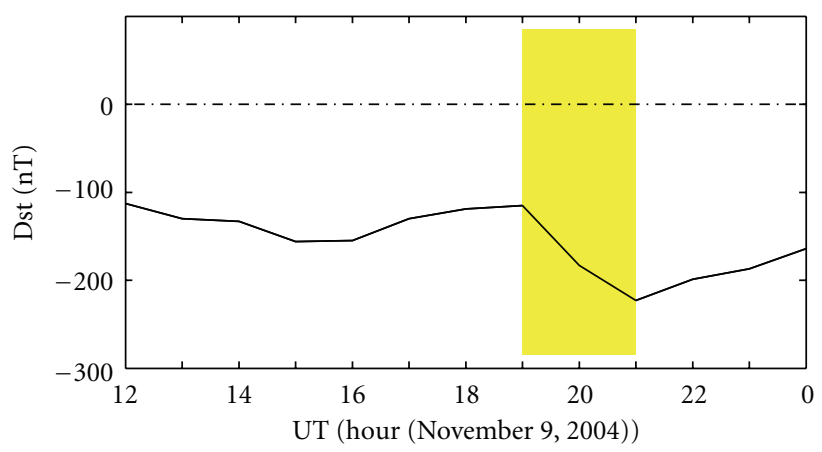

(d)

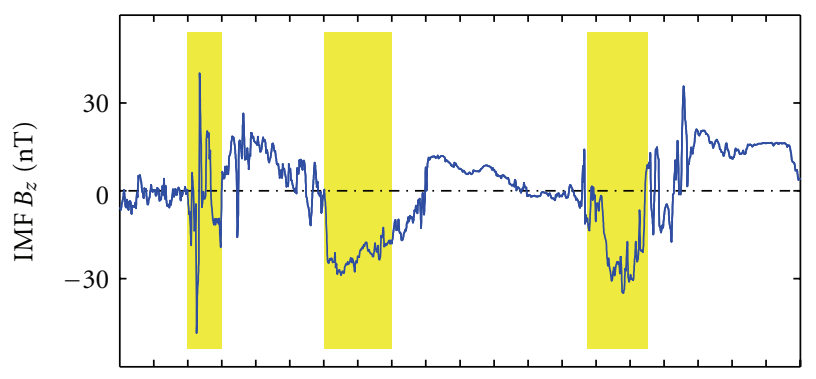

(e)

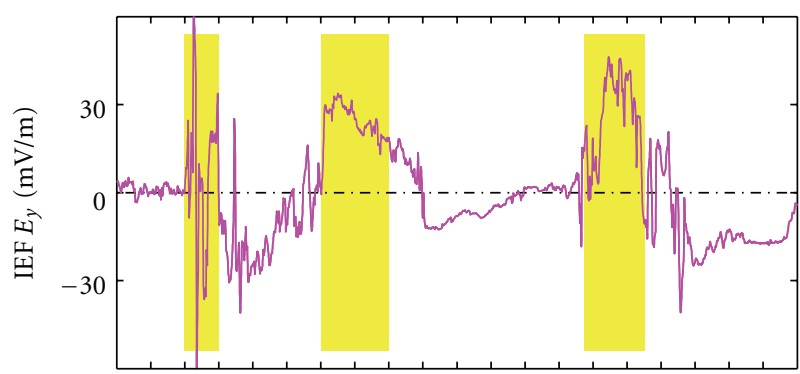

(f)

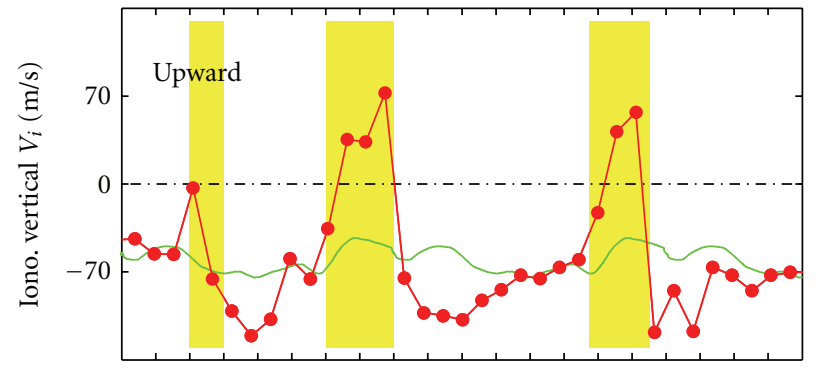

(g)

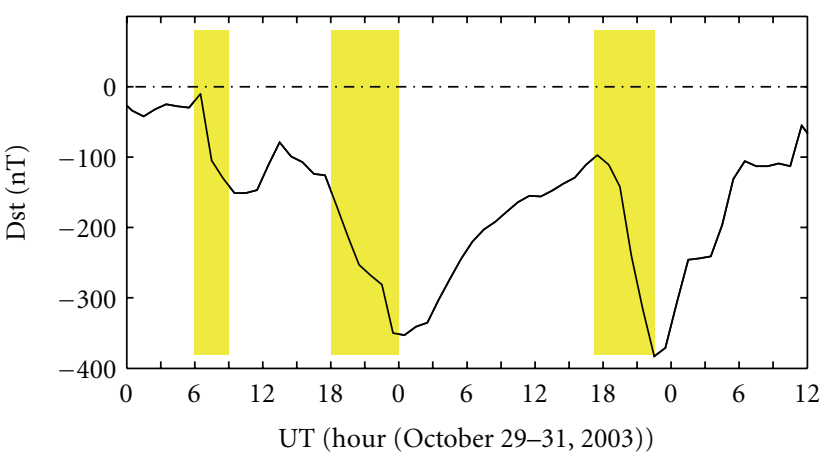

(h)

FIGURE 1: Examples of penetration electric fields during magnetic storms. Figures 1(a)-1(d) show interplanetary magnetic field (IMF) southnorth $\left(B_{z}\right)$ component, interplanetary electric field (IEF) dawn-dusk $\left(E_{y}\right)$ component, $(\mathrm{c})$ ion vertical velocity in the equatorial ionosphere measured by the Jicamarca incoherent scatter radar, and (d) Dst index on 9 November 2004, respectively. Figures 1(e)-1(h) show the case during 29-31 October 2003; the ion vertical velocity in Figure 1(g) was measured by the DMSP F13 satellite. The shaded regions denote the periods of southward IMF and enhanced vertical ion drift.

We focus on the generation of equatorial plasma bubbles following IMF southward turning during intense magnetic storms. Figure 2 depicts (a) the IMF $B_{z}$, (b) the ion density between $\pm 50^{\circ}$ magnetic latitudes measured by the DMSP F14 satellite at 2000 MLT, and (c) the ion density measured by the DMSP F15 satellite at 2130 MLT on 29 October 2003. The orbital period of the DMSP satellites is $\sim 102 \mathrm{~min}$, and each satellite has $\sim 14$ complete orbits every 24 hours. In Figure 2(a), UT is plotted as the vertical axis, and the yellow shadings denote the intervals of southward IMF. 


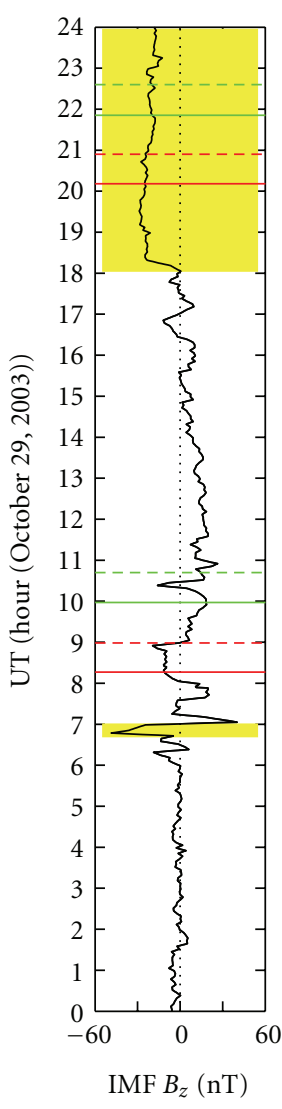

(a)

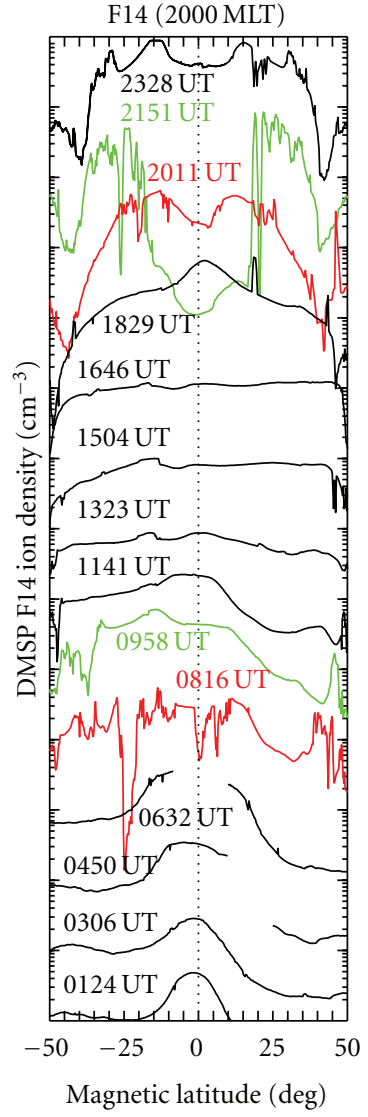

(b)

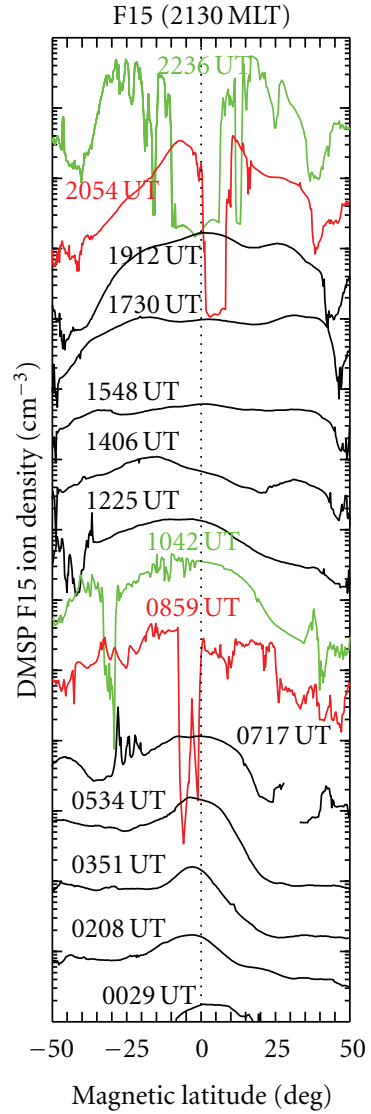

(c)

FIGURE 2: Occurrence of equatorial plasma bubbles during the periods of southward IMF on 29 October 2003. Figures 2(a)-2(c) show the IMF $B_{z}$ and the ionospheric ion density measured by the DMSP F14 and F15 satellites, respectively.

In Figures 2(b) and 2(c), the ion density is plotted in logarithm scale, and UT represents the time when the satellite crossed the magnetic equator. The ion density varies, in general, between $10^{3}$ and $10^{5} \mathrm{~cm}^{-3}$ in the latitude range of $\pm 50^{\circ}$. Because the ion density distributions over 14 orbits are plotted in Figure 2(b) (and Figure 2(c)), the density values are not marked for each specific orbit.

A strong southward turning of the IMF occurred between 0637 and $0656 \mathrm{UT}$, with a minimum value of $-48 \mathrm{nT}$, as denoted by the yellow shading in Figure 2(a). F14 detected significant ion density depletions at $0816 \mathrm{UT}$ (the red line in Figure 2(b)) and at 0958 UT (the green line in Figure 2(b)). Similarly, F15 detected significant ion density depletions at 0859 and 1042 UT. The solid horizontal red and green lines in Figure 2(a) denote the UT when F14 detected the ion density depletions, and the dashed red and green lines denote the times for F15. The ion density showed normal variations with latitude before $0800 \mathrm{UT}$, and the ion density depletions were detected shortly after the IMF southward turning. The time delay between the IMF southward turning at 0637 UT and the first detection of plasma depletions by F14 at $0816 \mathrm{UT}$ is $\sim 100 \mathrm{~min}$.

The IMF was generally northward between 0900 and 1800 UT, and the ionosphere became quiet again. The IMF became strongly southward after 1800 UT. F14 detected significant ion density depletions at 2011 and 2151 UT, and F15 detected ion density depletions at 2054 and 2236 UT. The time delay between the IMF southward turning at 1800 UT and the first detection of plasma depletions by F14 at 2011 UT is $\sim 2.2$ hours.

The data on 30 October 2003 presented in Figure 3 are the continuation of Figure 2 for the same storm case. The IMF remained southward until $0300 \mathrm{UT}$, and F15 detected ion density depletions at 0014 and 0153 UT. The IMF was mostly northward between 0300 and 1830 UT, with some fluctuations between 1600 and $1830 \mathrm{UT}$, and then became southward again after 1830 UT. F15 detected ion density depletions at 2039 UT and 2221 UT, and F14 detected ion density depletions at 2137 and 2315 UT. The time delay between the IMF southward turning at 1830 UT and the first detection of plasma depletions by F15 at 2039 UT is $\sim 2.1$ hours.

Figures 2 and 3 reveal important relationship between IMF orientation and occurrence of ionospheric plasma depletions. The ionosphere was rather quiet during the periods of northward IMF, and significant plasma depletions occurred $\sim 2$ hours after the IMF turned southward. The generation of the equatorial ionospheric plasma depletions was caused by the southward IMF. 


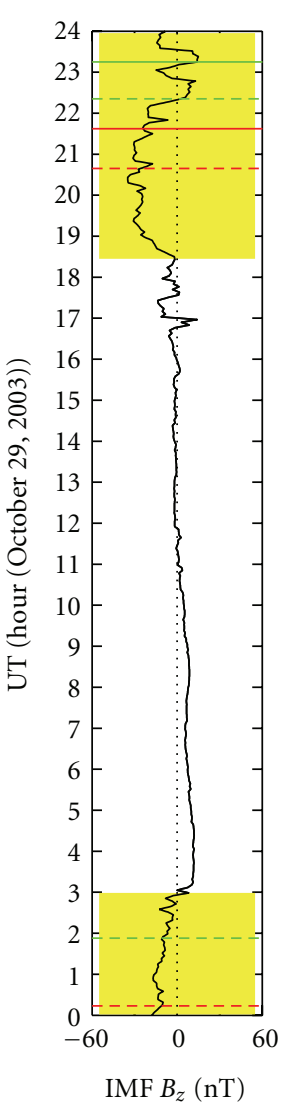

(a)

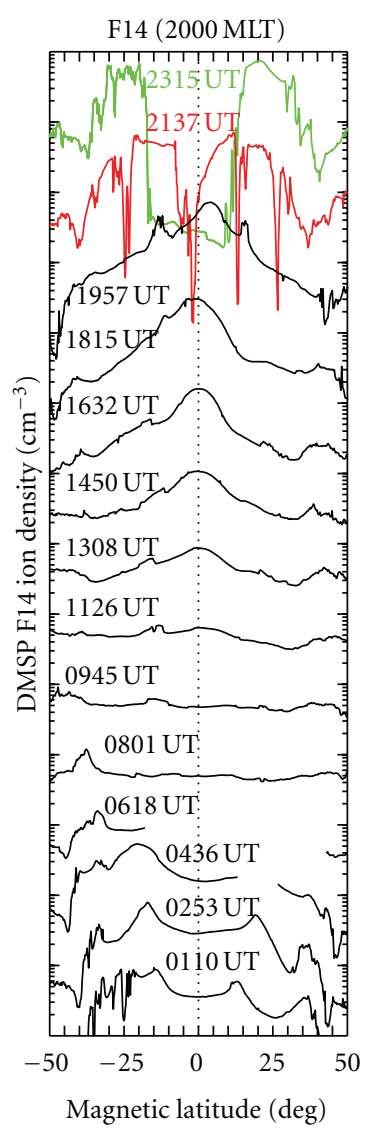

(b)

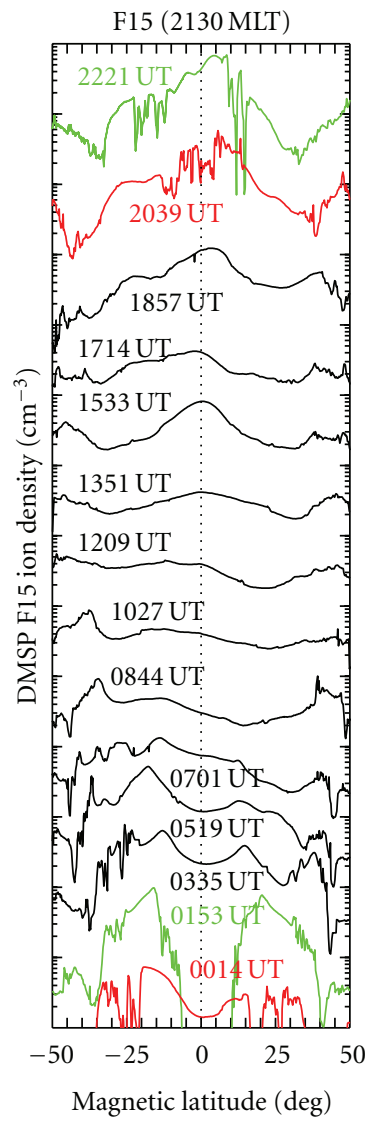

(c)

FIGURE 3: Occurrence of equatorial plasma bubbles during the periods of southward IMF on 30 October 2003. Figures 3(a)-3(c) show the IMF $B_{z}$ and the ionospheric ion density measured by the DMSP F14 and F15 satellites, respectively.

The deep ion density depletions in the low-latitude ionosphere are plasma bubbles. Equatorial plasma bubbles result from the nonlinear evolution of the Rayleigh-Taylor instability. A unique feature of plasma bubbles is the existence of large upward ion drift caused by polarization electric field inside the depletion region (e.g., [43]). In order to show this feature, we plot the ion density and ion vertical velocity in Figure 4. Figures 4(a) and 4(b) present the data measured by F15 around 0859 UT on 29 October 2003, and the shaded region denotes the ion density depletions. The ion density was decreased by $\sim 2$ orders of magnitude, and the upward ion velocity reached more than $2000 \mathrm{~m} \mathrm{~s}^{-1}$. The very large upward ion velocity is the plasma $\mathbf{E} \times \mathbf{B}$ drift caused by the polarization electric field and is the evidence that the plasma depletions are bubbles. The plasma particles inside bubbles are moved to high altitudes by upward $\mathbf{E} \times \mathbf{B}$ drifts and then flow down along the magnetic field lines to higher latitudes.

In Figures 4(c) and 4(d), the ion density and velocity were measured by F14 around 2137 UT on 30 October 2003. The upward ion velocity inside the depletions near the magnetic equator was enhanced, compared to the plasma drifts outside the depletion region. In contrast, the ion velocity became downward at $-25^{\circ}$ magnetic latitude. The magnetic field lines have large dip angle at $-25^{\circ}$ magnetic latitude. When the depleted magnetic flux associated with the equatorial plasma bubble reaches this latitude, the plasma flow has a significant component along the magnetic field lines. The downward ion velocity at higher latitudes was related to the field-aligned plasma flow.

The ion vertical velocity was upward inside the plasma depletions at $14^{\circ}$ magnetic latitude in Figure 4(d). The dip angle of the magnetic field lines at $14^{\circ}$ magnetic latitude is about $15^{\circ}$, and the ion vertical velocity might be dominated by the $\mathbf{E} \times \mathbf{B}$ drift and upward. At $-25^{\circ}$ magnetic latitude, the dip angle of the magnetic field lines is about $36^{\circ}$, and the ion vertical velocity could be dominated by the field-aligned plasma flow and become downward. In addition, the orbit of the DMSP satellite is not along the magnetic field lines. The plasma depletions at $14 \circ$ and $-25^{\circ}$ magnetic latitudes had a longitudinal difference of $\sim 10^{\circ}$ and could be two separate bubbles. The ion vertical velocity inside separate bubbles may behave differently.

It should be mentioned that low-latitude ionospheric plasma depletions can become very wide during intense magnetic storms. For example, deep plasma depletions measured by F14 at 2151 UT on 29 October 2003 (Figure 2(b)) and at 2315 UT on 30 October 2003 (Figure 3(b)) cover a latitudinal range of $30-40^{\circ}$. Such wide depletions are not the normal plasma bubbles. The wide plasma depletions are caused by continuous lifting of the $\mathrm{F}$ region driven by 


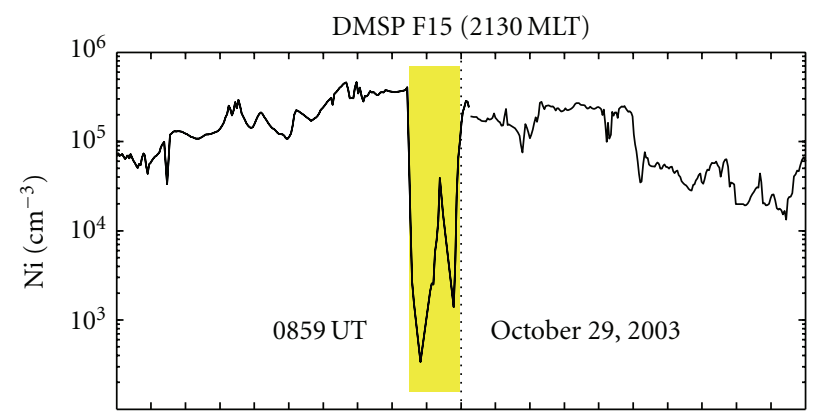

(a)

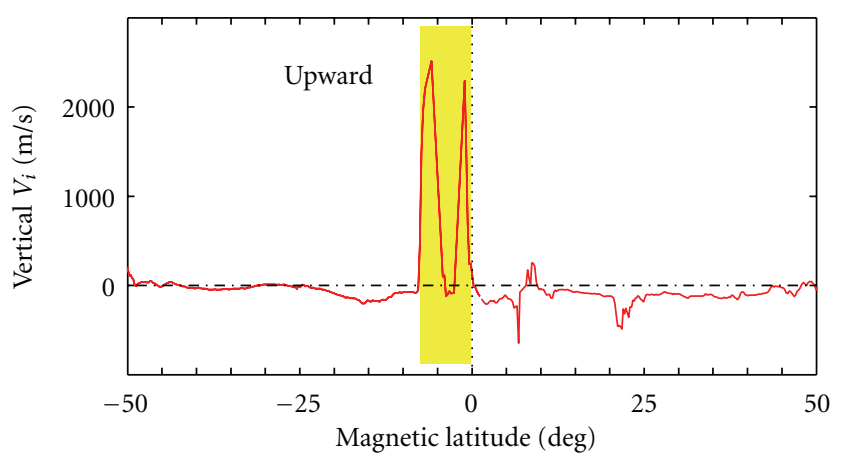

(b)

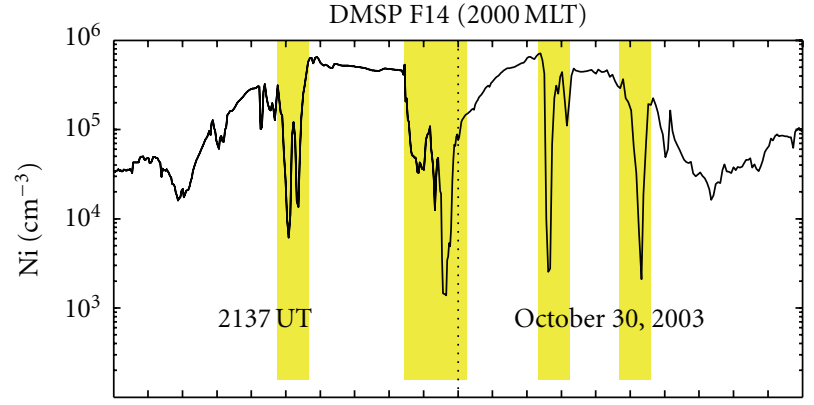

(c)

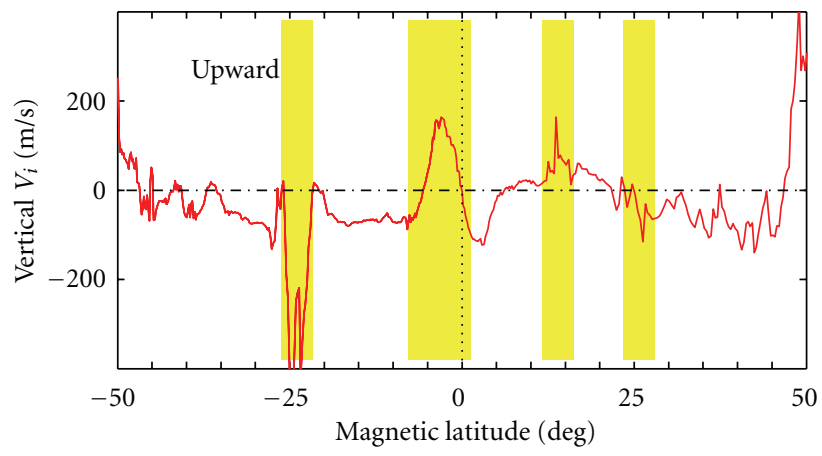

(d)

Figure 4: Latitudinal structures of ionospheric ion density and vertical ion drift associated with equatorial plasma bubbles. The shaded regions indicate ion density depletions (plasma bubbles).

strong penetration electric fields. When the entire F region has moved to altitudes higher than the DMSP orbit, the ion density at the DMSP orbit becomes very low. The wide plasma depletions result from the long-lasting penetration electric field during continuous southward IMF.

We now carry out a statistical analysis of the occurrence of equatorial plasma bubbles during intense magnetic storms and use the DMSP measurements for the identification of plasma bubbles. The orbital path of the DMSP satellites is at $840 \mathrm{~km}$ altitude. Any plasma bubbles that are below $840 \mathrm{~km}$ are not detected by the DMSP satellites. Our criterion for case selection is as follows. There are no plasma bubbles for $\sim 10$ hours before the IMF turns southward, and plasma bubbles occur shortly after the IMF southward turning. We assume that the occurrence of the plasma bubbles is the consequence of the IMF southward turning and penetration electric field.

We made a search of the Dst data over 1995-2005 and found 80 intense magnetic storms with minimum Dst value of less than $-100 \mathrm{nT}$. Almost all of the intense storms were associated with strong southward IMF. We then checked the DMSP measurements during these storms. In some storm cases, ion density depletions occurred both before and after IMF southward turning, and such cases are excluded in our analyses because we cannot determine whether the ion density depletions were related to the IMF southward turning. We finally found 22 storms that satisfy the criterion. The examples given in Figures 2 and 3 are from this set.

The Dst index during the 22 storms is plotted in Figure 5. The epoch time is chosen to be the time of the maximum Dst value just before the storm main phase, which generally corresponds to the initial phase of magnetic storms. The dot on the line of each individual storm represents the earliest time at which deep ion density depletions were detected by one DMSP satellite after the IMF southward turning. For example, in the case of the IMF southward turning at 0637 UT in Figure 2, the first detection of plasma depletions was made by the F14 satellite at $0816 \mathrm{UT}$, and we do not count the subsequent detections by F15 at 0859 UT, by F14 at $0958 \mathrm{UT}$, and by F15 at $1042 \mathrm{UT}$. In other words, each magnetic storm is counted only once in Figure 5. It can be seen that the first DMSP detections of ion density depletions occurred within 2-3 hours from the storm initial phase. The plasma depletions in the statistics include all events, irrespective of whether they are plasma bubbles generated by the Rayleigh-Taylor instability or larger-scale depletions caused by eastward penetration electric fields. In most cases, plasma bubbles with strong upward ion drift were first detected.

It should be noted that the initial phase of magnetic storms with an increase of the Dst index is generally caused by a sudden enhancement of the solar wind pressure and does not necessarily correspond to IMF southward turning. The penetration electric field, which lifts the equatorial ionosphere in the evening sector, is primarily determined by southward IMF. Therefore, we use the time delay between the IMF southward turning and the first detection of equatorial ion density depletions as a measure of the effect of penetration electric fields on the generation of equatorial plasma bubbles. 


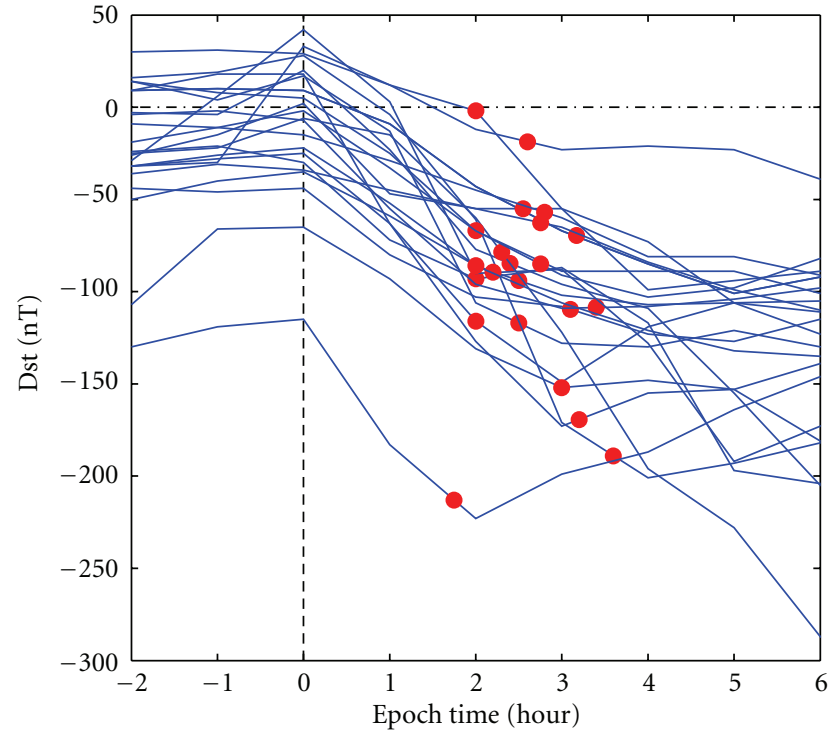

FIGURE 5: Epoch analysis of the Dst index during 22 intense magnetic storms. The dot in each storm case represents the time of the first detection of equatorial plasma density depletions (plasma bubbles) by a DMSP satellite in the evening sector.

Figure 6 shows how the time delay between IMF southward turning and the first detection of equatorial plasma bubbles varies with the minimum value of the IMF $B_{z}$, the maximum value of the IEF $E_{y}$, and the minimum Dst value. The time delay becomes shorter when the magnitude of southward IMF becomes larger (Figure 6(a)). The IEF $E_{y}$ is determined primarily by the IMF $B_{z}$. The IEF $E_{y}$ penetrates to the equatorial ionosphere in the evening sector and lifts the $\mathrm{F}$ region there. The larger the IEF $E_{y}$ is, the faster the $\mathrm{F}$ region moves upward. As a result, the equatorial plasma bubbles are generated within a shorter time, so the time delay becomes shorter when the IEF $E_{y}$ is larger (Figure 6(b)). The time delay also becomes shorter when the absolute value of the minimum Dst is larger (Figure 6(c)), implying that the time delay is shorter during stronger storms. The results in Figure 6 demonstrate the role of southward IMF and penetration electric field in the generation of equatorial plasma bubbles.

The average time delay between IMF southward turning and the first detection of plasma bubbles by one DMSP satellite is $142 \mathrm{~min}$ in the 22 storm cases. The DMSP satellites may not be able to detect all plasma bubbles. Measurements from four DMSP satellites are available in most cases of our study. The orbit of the F13 satellite is close to the dawn-dusk meridian plane around $1800 \mathrm{LT}$. The local time interval with high occurrence probability of plasma bubbles is between 1900-2200 LT (e.g., [34]), and F13 is generally outside the bubble region. A complete DMSP orbit surrounding the Earth takes $\sim 102 \mathrm{~min}$. If there are three satellites flying across the bubble region, the bubble region will be sampled, on average, every $\sim 35 \mathrm{~min}$. The longitudinal (or local time) coverage of a plasma bubble is limited, and the bubble cannot be seen by a satellite if the satellite orbit does not go exactly through the bubble. Furthermore, the orbital altitude of the DMSP satellites is $\sim 840 \mathrm{~km}$, and all plasma bubbles below
$840 \mathrm{~km}$ are not detected by the satellites. The yellow shadings in Figure 6 cover most data points, and the data scatter in Figure 6 is caused by these characteristics of the DMSP measurements. It is certain that the satellites will miss some bubbles. In other words, there are more plasma bubbles than the DMSP measurements. Therefore, the real-time delay between the IMF southward turning and the generation of plasma bubbles should be shorter than $142 \mathrm{~min}$. Although some uncertainties exist in the DMSP measurements of plasma bubbles, Figure 6 clearly indicates that the time delay decreases with the minimum value of the IMF $B_{z}$, the maximum value of the IEF $E_{y}$, and the strength of magnetic storms.

\section{Discussion}

The penetration electric field after IMF southward turning is eastward on the dayside and westward on the nightside. However, the reversal of the penetration electric field does not occur at the dawn-dusk meridian (0600-1800 LT). The numerical simulations [15-18] show that the low-latitude penetration electric field is eastward in the evening sector and that the reversal occurs at 2200-2300 LT. The DMSP satellite measurements presented in the right column of Figure 1 show that penetration electric field at dusk is indeed eastward. The eastward penetration electric field will move the $\mathrm{F}$ region to higher altitudes. When the lifted $\mathrm{F}$ region reaches the height where the ion-neutral collision frequency is small enough, the Rayleigh-Taylor instability will grow rapidly, resulting in the generation of equatorial plasma bubbles. The time delay in Figure 6 is the delay between the IMF southward turning and the first detection of ion density depletions. The Rayleigh-Taylor instability must have been excited in the bottomside $\mathrm{F}$ region at earlier times.

The IMF is in general strongly southward during the main phase of intense magnetic storms. As shown in Figure 6, the time delay between IMF southward turning and plasma bubble detection becomes shorter as the magnitude of the IMF $B_{z} /$ IEF $E_{y}$ increases. In particular, plasma bubbles can reach the DMSP orbital altitude of $840 \mathrm{~km}$ within $100 \mathrm{~min}$ from IMF southward turning in a number of cases. The observed variations of the time delay with the Dst index and IMF/IEF justify the effect of penetration electric fields on the generation of ESF plasma bubbles.

Equatorial plasma bubbles often cause ionospheric scintillations. Scintillations are primarily generated near the boundary of plasma bubbles where the plasma density gradient is large. When the storm-time eastward penetration electric field is extremely strong, the equatorial $\mathrm{F}$ region in the evening sector can be moved to very high altitudes, and significant plasma depletions are formed over a large latitudinal range. As shown in Figure 2(b), the plasma density measured by the DMSP F14 satellite at 2151 UT became extremely low between $\pm 20^{\circ}$ magnetic latitudes. The latitudinal variation of the plasma density inside the depletion region was gradual and smooth, and large density gradient existed only at the boundaries. In such cases, strong scintillations occur near the boundaries of the depletion region, and only weak scintillations occur in the low-density 


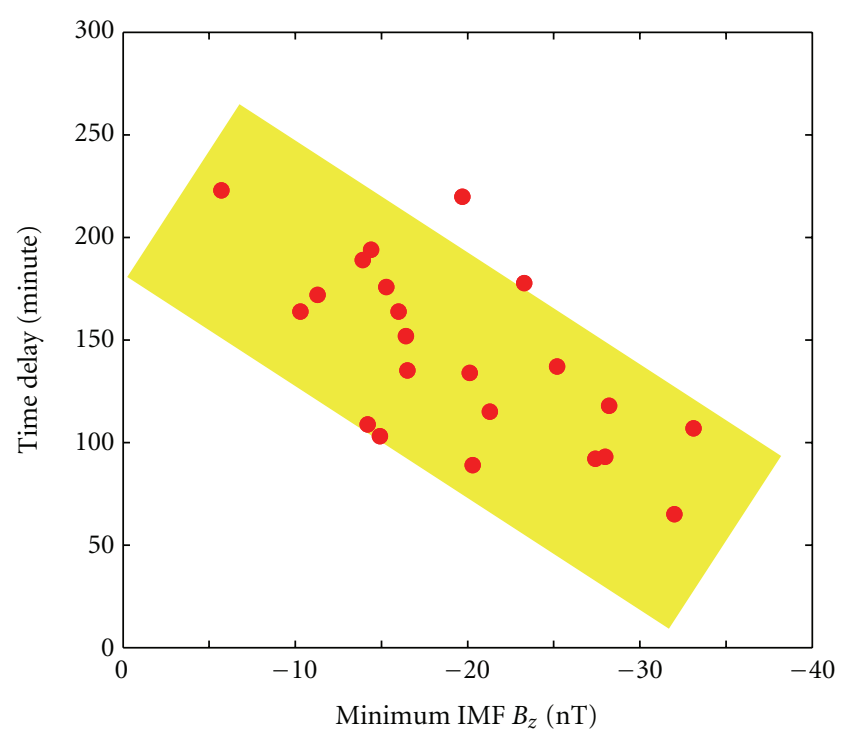

(a)

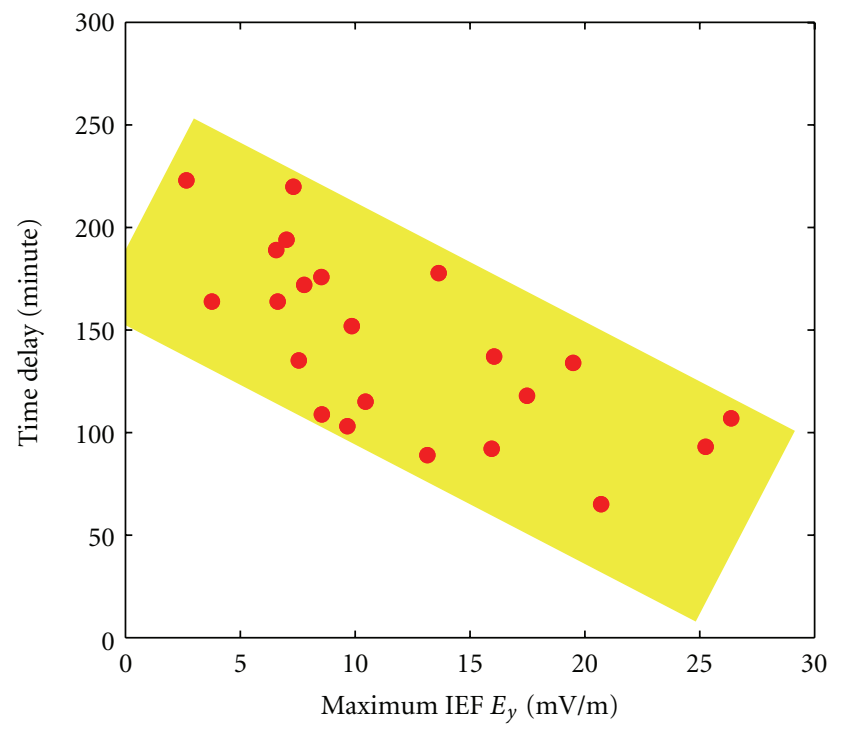

(b)

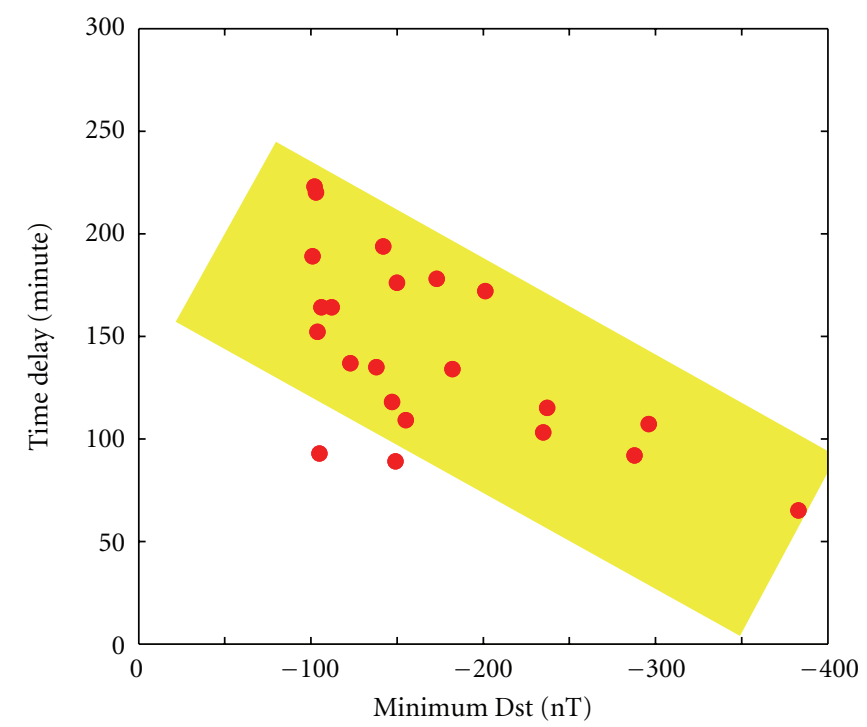

(c)

FIGURE 6: The time delay between IMF southward turning and first DMSP detection of equatorial plasma depletions as a function of (a) the minimum value of the IMF $B_{z}$, (b) the maximum value of the IEF $E_{y}$, and (c) the minimum Dst value during intense magnetic storms.

region. Abdu et al. [44] have analyzed the characteristics of ionospheric scintillations in the Brazilian sector during the magnetic storm on 30 October 2003.

Some previous studies [33-36] found that enhanced magnetic activity suppressed the occurrence of plasma bubbles in the evening sector. Neutral wind disturbances generated in the auroral zone during magnetic storms take several hours to reach the equatorial ionosphere and create westward electric field in the evening equatorial ionosphere. The westward dynamo electric field causes the equatorial $\mathrm{F}$ region to move downward, inhibiting the excitation of the RayleighTaylor instability. The suppression of ESF and plasma bubbles in the previous studies might be related to the disturbance dynamo and occur during the storm recovery phase rather than the main phase.
The main phase of magnetic storms occurs during southward IMF, and the recovery phase generally starts when the IMF turns northward. In the storm case on 9 November 2004 (Figures 1(a)-1(d)), the IMF turned northward at 2043 UT through $\sim 0400 \mathrm{UT}$ on the next day. Overshielding electric field occurs during northward IMF [2] and will cause downward plasma drift in the evening equatorial ionosphere. The Jicamarca radar indeed measured downward ion velocity after 2043 UT, consistent with the scenario of overshielding electric field. This effect of northward IMF also contributes to the suppression of ESF and plasma bubbles during the recovery phase of magnetic storms. Abdu et al. [45] found that the evening prereversal enhancement in the vertical plasma drift and the consequent spread $\mathrm{F}$ generation can be totally suppressed by the overshielding electric field with 
westward polarity. Our observations are consistent with the results of Abdu et al. [45].

\section{Conclusions}

We have presented the DMSP satellite measurements of the ion density and velocity at $840-\mathrm{km}$ altitude in the evening sector during the main phase of 22 intense magnetic storms with minimum Dst value of smaller than $-100 \mathrm{nT}$. It is shown that the penetration electric field at dusk is eastward and can last for several hours without effective shielding during continuous southward IMF as long as the geomagnetic activity is strengthening. The eastward penetration electric field moves the equatorial $\mathrm{F}$ region to higher altitudes conducive for the generation of plasma bubbles. The time delay between the IMF southward turning and the first DMSP detection of equatorial plasma depletions/bubbles is in the range of 70-220 min, with a mean value of $142 \mathrm{~min}$, during the 22 magnetic storms. The time delay decreases with the minimum value of the IMF $B_{z}$, the maximum value of the IEF $E_{y}$ after IMF southward turning, and the magnitude of the Dst index. In particular, the time delay becomes shorter when the value of the maximum IEF $E_{y}$ is larger, indicating the effect of penetration electric fields on the generation of plasma bubbles. The IMF is in general strongly southward during the main phase of intense magnetic storms. The results of this study suggest that more plasma bubbles are expected to occur during the storm main phase and that plasma bubbles are generated more rapidly under stronger southward IMF conditions.

\section{Acknowledgments}

This work was supported by the Air Force Office of Scientific Research (AFOSR) Award FA9550-09-1-0321. The authors gratefully acknowledge the Center for Space Sciences at the University of Texas at Dallas and the US Air Force for providing the DMSP thermal plasma data. The Jicamarca Radio Observatory is operated by the Instituto Geofisico del Peru, with support from the NSF Cooperative Agreement ATM-0432565 through Cornell University. They thank the CDAWeb for providing access to the solar wind and Dst data.

\section{References}

[1] A. Nishida, "Coherence of geomagnetic DP2 fluctuations with interplanetary magnetic variations," Journal of Geophysical Research A, vol. 73, no. 17, pp. 5549-5559, 1968.

[2] M. C. Kelley, B. G. Fejer, and C. A. Gonzales, "An explanation for anomalous equatorial ionospheric electric field associated with a northward turning of the interplanetary magnetic field," Geophysical Research Letters, vol. 6, no. 4, pp. 301-304, 1979.

[3] B. G. Fejer, C. A. Gonzales, D. T. Farley, M. C. Kelley, and R. F. Woodman, "equatorial electric fields during magnetically disturbed conditions, 1 . The effect of the interplanetary magnetic field ," Journal of Geophysical Research, vol. 84, no. 10, pp. 5797-5802, 1979.

[4] T. Kikuchi, H. Luhr, T. Kitamura, O. Saka, and K. Schlegel, "Direct penetration of the polar electric field to the equator during a DP 2 event as detected by the auroral and equatorial magnetometer chains and the EISCAT radar," Journal of Geophysical Research A, vol. 101, no. 8, pp. 17,161-17,173, 1996.

[5] M. C. Kelley, J. J. Makela, J. L. Chau, and M. J. Nicolls, "Penetration of the solar wind electric field into the magnetosphere/ionosphere system," Geophysical Research Letters, vol. 30, no. 4, Article ID 1158, 3 pages, 2003.

[6] C. S. Huang, J. C. Foster, L. P. Goncharenko, P. J. Erickson, W. Rideout, and A. J. Coster, "A strong positive phase of ionospheric storms observed by the Millstone Hill incoherent scatter radar and global GPS network," Journal of Geophysical Research A, vol. 110, no. 6, Article ID A06303, 13 pages, 2005.

[7] C. S. Huang, J. C. Foster, and M. C. Kelley, "Long-duration penetration of the interplanetary electric field to the low-latitude ionosphere during the main phase of magnetic storms," Journal of Geophysical Research A, vol. 110, no. 11, Article ID A11309, 13 pages, 2005.

[8] C. S. Huang, S. Sazykin, J. L. Chau, N. Maruyama, and M. C. Kelley, "Penetration electric fields: efficiency and characteristic time scale," Journal of Atmospheric and Solar-Terrestrial Physics, vol. 69, no. 10-11, pp. 1135-1146, 2007.

[9] B. G. Fejer, J. W. Jensen, T. Kikuchi, M. A. Abdu, and J. L. Chau, "Equatorial ionospheric electric fields during the November 2004 magnetic storm," Journal of Geophysical Research A, vol. 112, no. 10, Article ID A10304, 11 pages, 2007.

[10] H. Kil, S. J. Oh, L. J. Paxton, Y. Zhang, S. Y. Su, and K. W. Min, "Spike-like change of the vertical $\mathbf{E} \times \mathbf{B}$ drift in the equatorial region during very large geomagnetic storms," Geophysical Research Letters, vol. 34, no. 9, Article ID L09103, 4 pages, 2007.

[11] C. S. Huang, "Continuous penetration of the interplanetary electric field to the equatorial ionosphere over eight hours during intense geomagnetic storms," Journal of Geophysical Research A, vol. 113, no. 11, Article ID A11305, 10 pages, 2008.

[12] T. Kikuchi, K. K. Hashimoto, and K. Nozaki, "Penetration of magnetospheric electric fields to the equator during a geomagnetic storm," Journal of Geophysical Research A, vol. 113, no. 6, Article ID A06214, 10 pages, 2008.

[13] M. C. Kelley and J. Retterer, "First successful prediction of a convective equatorial ionospheric storm using solar wind parameters," Space Weather, vol. 6, no. 8, Article ID S08003, 4 pages, 2008.

[14] C. S. Huang, F. J. Rich, and W. J. Burke, "Storm time electric fields in the equatorial ionosphere observed near the dusk meridian," Journal of Geophysical Research A, vol. 115, no. 8, Article ID A08313, 14 pages, 2010.

[15] R. W. Spiro, R. A. Wold, and B. G. Fejer, "Penetration of highlatitude-electric-field effects to low latitudes during SUNDIAL 1984," Annales Geophysicae, vol. 6, no. 1, pp. 39-50, 1988.

[16] B. G. Fejer, R. W. Spiro, R. A. Wolf, and J. C. Foster, "Latitudinal variations of penetration electric fields during magnetically disturbed periods: 1986 SUNDIAL observations and model results," Annales Geophysicae, vol. 8, no. 6, pp. 441454, 1990.

[17] J. D. Huba, G. Joyce, S. Sazykin, R. Wolf, and R. Spiro, "Simulation study of penetration electric field effects on the low- to mid-latitude ionosphere," Geophysical Research Letters, vol. 32, no. 23, Article ID L23101, 4 pages, 2005.

[18] N. Maruyama, A. D. Richmond, T. J. Fuller-Rowell et al., "Interaction between direct penetration and disturbance dynamo electric fields in the storm-time equatorial ionosphere," Geophysical Research Letters, vol. 32, no. 17, Article ID L17105, 4 pages, 2005. 
[19] R. F. Woodman and C. La Hoz, "Radar observations of F-region equatorial irregularities," Journal of Geophysical Research, vol. 81, no. 31, pp. 5447-5466, 1976.

[20] A. J. Scannapieco and S. L. Ossakow, "Nonlinear spread-F," Geophysical Research Letters, vol. 3, no. 8, pp. 451-454, 1976.

[21] S. L. Ossakow and P. K. Chaturvedi, "Morphological studies of rising equatorial spread F bubbles," Journal of Geophysical Research A, vol. 83, no. 5, pp. 2085-2090, 1978.

[22] S. T. Zalesak, S. L. Ossakow, and P. K. Chaturvedi, "Nonlinear equatorial spread-F: the effect of neutral winds and background Pedersen conductivity," Journal of Geophysical Research A, vol. 87, no. 1, pp. 151-166, 1982.

[23] C. S. Huang and M. C. Kelley, "Nonlinear evolution of equatorial spread F: 1 . On the role of plasma instabilities and spatial resonance associated with gravity wave seeding," Journal of Geophysical Research A, vol. 101, no. 1, pp. 283-292, 1996.

[24] C. S. Huang and M. C. Kelley, "Nonlinear evolution of equatorial spread F: 2. Gravity wave seeding of Rayleigh-Taylor instability," Journal of Geophysical Research A, vol. 101, no. 1, pp. 293-302, 1996.

[25] M. J. Keskinen, S. L. Ossakow, and B. G. Fejer, "Threedimensional nonlinear evolution of equatorial ionospheric spread-F bubbles," Geophysical Research Letters, vol. 30, no. 16, Article ID 1855, 4 pages, 2003.

[26] M. J. Keskinen, S. L. Ossakow, B. G. Fejer, and J. Emmert, "Evolution of equatorial ionospheric bubbles during a large auroral electrojet index increase in the recovery phase of a magnetic storm," Journal of Geophysical Research A, vol. 111, no. 2, Article ID A02303, 5 pages, 2006.

[27] J. D. Huba, J. Krall, and G. Joyce, "Atomic and molecular ion dynamics during equatorial spread F," Geophysical Research Letters, vol. 36, no. 10, Article ID L10106, 6 pages, 2009.

[28] J. D. Huba, S. L. Ossakow, G. Joyce, J. Krall, and S. L. England, "Three-dimensional equatorial spread F modeling: zonal neutral wind effects," Geophysical Research Letters, vol. 36, no. 19, Article ID L19106, 5 pages, 2009.

[29] J. Krall, J. D. Huba, S. L. Ossakow, and G. Joyce, "Why do equatorial ionospheric bubbles stop rising?" Geophysical Research Letters, vol. 37, no. 9, Article ID L09105, 4 pages, 2010.

[30] J. Krall, J. D. Huba, G. Joyce, and T. Yokoyama, "Density enhancements associated with equatorial spread F," Annales Geophysicae, vol. 28, no. 2, pp. 327-337, 2010.

[31] J. M. Retterer, "Forecasting low-latitude radio scintillation with 3-D ionospheric plume models: 1. Plume model," Journal of Geophysical Research A, vol. 115, no. 3, Article ID A03306, 18 pages, 20110.

[32] J. M. Retterer, "Forecasting low-latitude radio scintillation with 3-D ionospheric plume models: 2 . Scintillation calculation," Journal of Geophysical Research A, vol. 115, no. 3, Article ID A03307, 10 pages, 2010.

[33] R. G. Rastogi, J. P. Mullen, and E. MacKenzie, "Effect of geomagnetic activity on equatorial radio VHF scintillations and spread F," Journal of Geophysical Research A, vol. 86, no. 5, pp. 3661-3664, 1981.

[34] S. Watanabe and H. Oya, "Occurrence characteristics of low latitude ionosphere irregularities observed by impedance probe on board the Hinotori satellite," Journal of Geomagnetism \& Geoelectricity, vol. 38, no. 1, pp. 125-149, 1986.

[35] S. Singh, D. K. Bamgboye, J. P. McClure, and F. S. Johnson, "Morphology of equatorial plasma bubbles," Journal of Geophysical Research A, vol. 102, no. 9, Article ID 97JA01724, pp. 20019-20029, 1997.
[36] M. Palmroth, H. Laakso, B. G. Fejer, and R. F. Pfaff Jr., "DE 2 observations of morningside and eveningside plasma density depletions in the equatorial ionosphere," Journal of Geophysical Research A, vol. 105, no. 8, Article ID 1999JA005090, pp. 18429-18442, 2000.

[37] B. G. Fejer, L. Scherliess, and E. R. de Paula, "Effects of the vertical plasma drift velocity on the generation and evolution of equatorial spread F," Journal of Geophysical Research A, vol. 104, no. 9, Article ID 1999JA900271, pp. 19859-19869, 1999.

[38] C. Y. Huang, W. J. Burke, J. S. Machuzak, L. C. Gentile, and P. J. Sultan, "DMSP observations of equatorial plasma bubbles in the topside ionosphere near solar maximum," Journal of Geophysical Research A, vol. 106, no. 5, pp. 8131-8142, 2001.

[39] C. Y. Huang, W. J. Burke, J. S. Machuzak, L. C. Gentile, and P. J. Sultan, "Equatorial plasma bubbles observed by DMSP satellites during a full solar cycle: toward a global climatology," Journal of Geophysical Research A, vol. 107, no. 12, Article ID 1434, 10 pages, 2002.

[40] S. Basu, S. Basu, K. M. Groves et al., "Response of the equatorial ionosphere in the South Atlantic region to the great magnetic storm of July 15, 2000," Geophysical Research Letters, vol. 28, no. 18, pp. 3577-3580, 2001.

[41] S. Basu, S. Basu, F. J. Rich et al., "Response of the equatorial ionosphere at dusk to penetration electric fields during intense magnetic storms," Journal of Geophysical Research A, vol. 112, no. 8, Article ID A08308, 14 pages, 2007.

[42] D. R. Weimer, D. M. Ober, N. C. Maynard et al., "Predicting interplanetary magnetic field (IMF) propagation delay times using the minimum variance technique," Journal of Geophysical Research A, vol. 108, no. 1, Article ID 1026, 12 pages, 2003.

[43] C. S. Huang, O. de La Beaujardiere, R. F. Pfaff et al., "Zonal drift of plasma particles inside equatorial plasma bubbles and its relation to the zonal drift of the bubble structure," Journal of Geophysical Research A, vol. 115, no. 7, Article ID A07316, 12 pages, 2010.

[44] M. A. Abdu, E. R. de Paula, I. S. Batista et al., "Abnormal evening vertical plasma drift and effects on ESF and EIA over Brazil-South Atlantic sector during the 30 October 2003 superstorm," Journal of Geophysical Research A, vol. 113, no. 7, Article ID A07313, 12 pages, 2008.

[45] M. A. Abdu, E. A. Kherani, I. S. Batista, and J. H. A. Sobral, "Equatorial evening prereversal vertical drift and spread F suppression by disturbance penetration electric fields," Geophysical Research Letters, vol. 36, no. 19, Article ID L19103, 5 pages, 2009. 

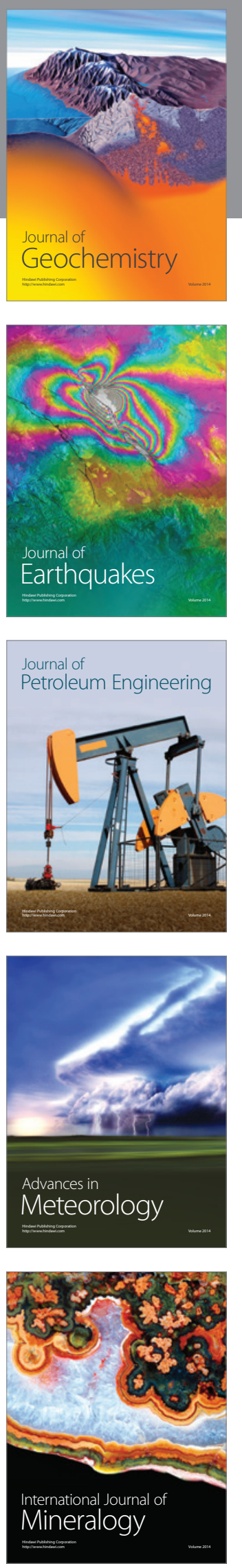
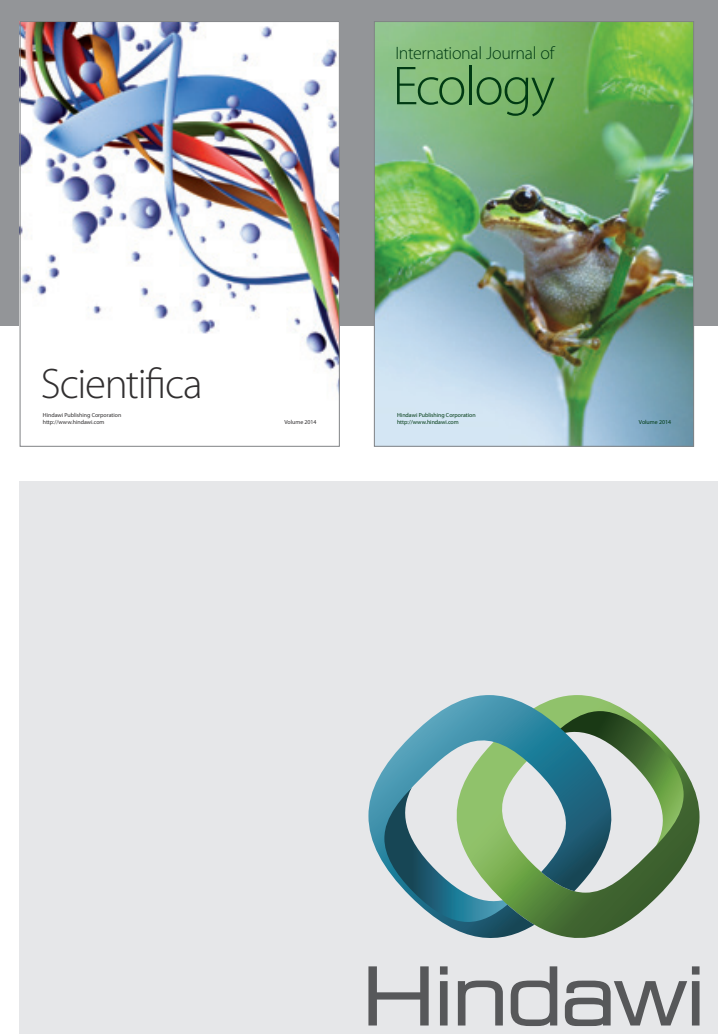

Submit your manuscripts at http://www.hindawi.com
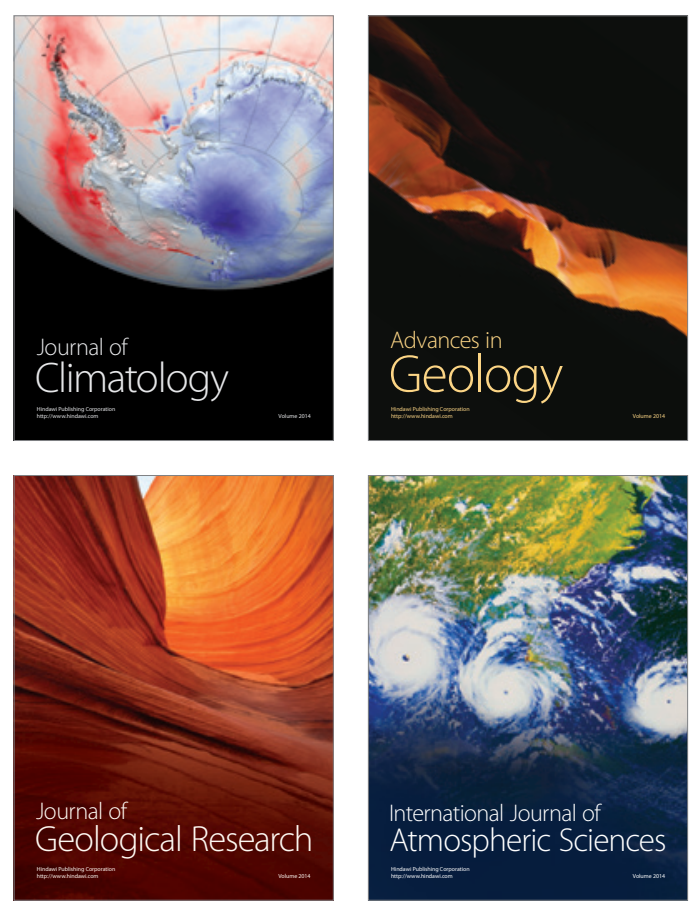
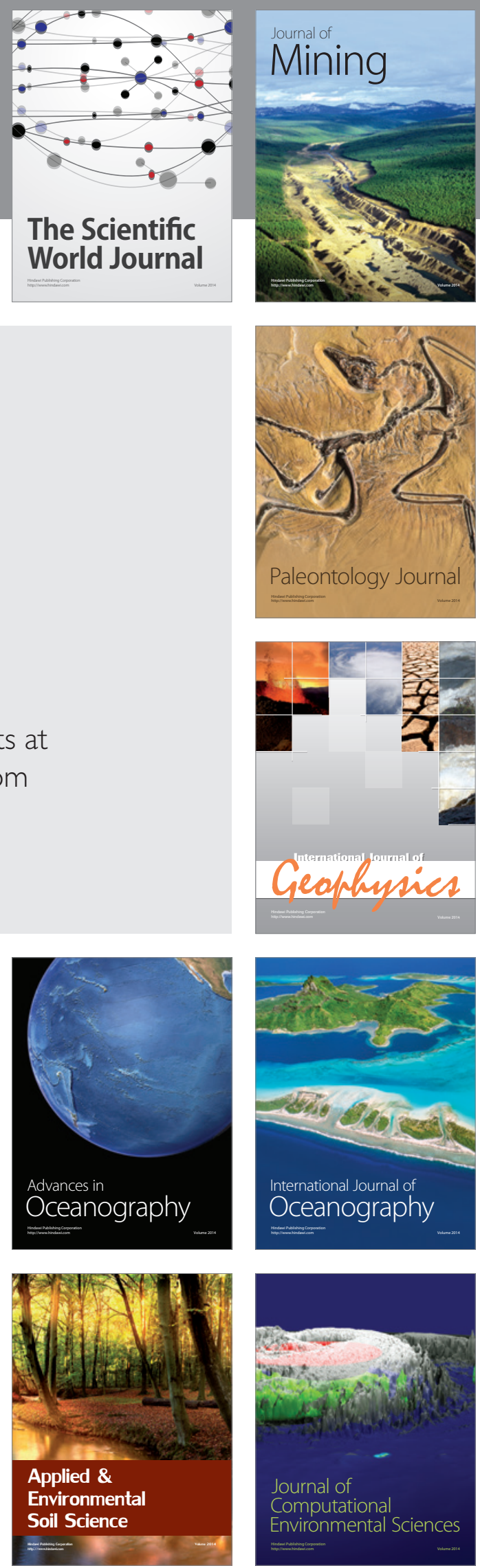